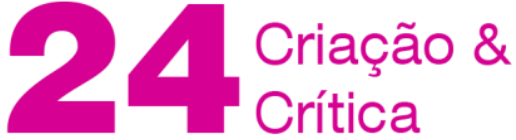

\section{DEVORANDO SHAKESPEARE EM \\ UM SONHO BRASILEIRO DE UMA NOITE DE VERÃO}

\author{
Caio Antônio Nóbrega ${ }^{1}$ \\ Genilda Azerêdo²
}

\begin{abstract}
Resumo: Neste artigo, objetivamos analisar o romance Sonho de uma noite de verão (2007), escrito por Adriana Falcão e publicado como parte da Coleção Devorando Shakespeare. Mais especificamente, pretendemos examinar como o próprio Shakespeare, através de um processo de releitura antropofágico e paródico, foi recriado como personagem dessa narrativa. Apesar de ser por vezes apontado como símbolo dos valores e ideologias ocidentais/modernos/colonialistas, Shakespeare pode também ser percebido e utilizado como um potente remédio ou antídoto criado no/pelo Sul. Através de uma desobediência epistêmica e da recuperação intercultural e ambivalente da figura de Shakespeare em meio às práticas e costumes do Carnaval de Salvador, defendemos que Falcão cria uma narrativa brasileira descolonial, capaz de antropofágica e parodicamente subverter discursos hegemônicos do Norte.
\end{abstract}

PALAVRAS-CHAVE: Shakespeare; antropofagia; paródia; desobediência epistêmica; descolonialidade.

\section{DEVOURING SHAKESPEARE IN A BRAZILIAN MIDSUMMER NIGHT’S DREAM}

ABSTRACT: In this paper, we aim at analyzing Adriana Falcão's Sonho de uma noite verão, published in 2007 as part of the collection Devouring Shakespeare. More specifically, we intend to examine how Shakespeare himself was recreated as a character in this narrative by means of parody and anthropophagy. Although usually associated with Western/modern/colonialist values and ideologies, Shakespeare may also be perceived and employed as a powerful remedy or antidote created in/by the South. Through epistemic disobedience and an intercultural and ambivalent actualization of Shakespeare as a character amid the festivities of the Carnival in Salvador, Falcão creates a Brazilian decolonial narrative, which subverts the hegemonic discourses from the North via anthropophagy and parody.

KEYWORDS: Shakespeare; anthropophagy; parody; epistemic disobedience; decoloniality.

\section{Introdução}

A coleção Devorando Shakespeare, publicada entre 2006 e 2007 pela Editora Objetiva, é composta por três livros que se constituem como releituras paródicas, na forma de romances, de três peças cômicas do dramaturgo e poeta inglês William Shakespeare. Primeira obra da coleção, Trabalhos de amor perdidos, de Jorge Furtado (2006), retoma a trama da peça homônima de Shakespeare. Luis Fernando Verissimo

1 UFPB, Mestre em Letras, caioamnobrega@gmail.com

2 UFPB, Professora dos cursos de Graduação e Pós-Graduação em Letras, genildaazeredo@yahoo.com 


\section{Criação \&}

(2006) é o escritor de $A$ décima segunda noite (2006), intertexto construído a partir da comédia Noite de Reis. O terceiro e último romance da coleção, Sonho de uma noite de verão, foi escrito por Adriana Falcão (2007) tendo como base os eventos da celebrada peça que empresta seu título à narrativa brasileira.

Como o próprio título da coleção já indicia, os três romances, através de uma prática antropofágica, releem enredos, espaços e personagens ingleses renascentistas, transpondo-os para o Brasil da contemporaneidade. O grande distanciamento temporal, geográfico e político-ideológico entre (a Inglaterra de) Shakespeare e (os Brasis de) Furtado, Verissimo e Falcão é responsável pelo desencadeamento de uma série de (des)encontros e tensões em níveis textuais e culturais, que muito têm a informar em termos de práticas artísticas contemporâneas.

Neste artigo, voltaremos nossa atenção para o terceiro e último romance da coleção, Sonho de uma noite de verão, escrito por Adriana Falcão. Nessa narrativa, a escritora transporta para as ruas de Salvador, durante o carnaval baiano, os acontecimentos que, na peça de Shakespeare, antecedem um casamento da nobreza, marcado por encontros e desencontros amorosos entre dois casais, que vagam por um bosque povoado por elfos e fadas. Teseu, Duque de Atenas, e Hipólita, Rainha das Amazonas, são atualizados como um candidato a senador e uma ex-atriz, que protagonizarão uma cerimônia de casamento bastante espetacularizada, sendo o centro das atenções da imprensa nos camarotes do carnaval soteropolitano. Também Lisandro e Demétrio são políticos no romance brasileiro, fazendo com que as idas e vindas amorosas ironicamente espelhem as trocas de partidos e favores escusos do mundo político. A recuperação do elemento fantástico, a partir da atuação das fadas e elfos (que ironicamente são enviados por Hera, rainha do Olimpo, em uma missão para averiguar a existência de humanos), acentua a sensação de vale tudo, que marca a festa de carnaval e a narrativa de Falcão.

Para além da atualização do enredo da comédia renascentista e da imbricação das culturas grega (acionada por Shakespeare e reacionada por Falcão), inglesa e brasileira, Falcão, em seu projeto de devoração de Shakespeare, acaba por recriá-lo como personagem de sua narrativa. Mais precisamente, a figura do Bardo está diretamente relacionada a dois personagens de sua trama: ao Deus das Histórias, chamado Shakespeare, que faz parte do panteão de deuses e seres mágicos comandado por Hera, e a Seu Biu, o dono de um bar muito frequentado durante o carnaval de Salvador. Ambos os personagens, por sua vez, têm uma ligação bastante próxima entre si, pois após Seu Biu tomar uma grande quantidade de cachaça, ele acaba por incorporar o Deus das Histórias, tornando-se William Shakespeare em Terra Brasilis - poeta, dramaturgo, criador de conflitos, beberrão, homem da barbicha e pai de santo.

E é exatamente essa recuperação paródica e irônica da figura de Shakespeare por Falcão, em seu Sonho de uma noite de verão, que será o foco de atenção neste artigo. Buscaremos, com nossa análise do romance, responder às seguintes perguntas: por que devorar Shakespeare no Brasil contemporâneo - o que pode ter motivado a 


\section{Criação \&}

criação do romance e do(s) próprio(s) personagem(s)?; de que forma ocorreu a devoração - quais estratégias foram utilizadas por Falcão ao reescrever Shakespeare em sua narrativa?; quais são as consequências da recuperação antropofágica da figura do Bardo na narrativa brasileira contemporânea - ou seja, qual a reverberação política do discurso irônico e ambivalente direcionado a um autor tão relevante e significativo do Norte Ocidental (ou da Metrópole)?

Para buscar responder a essas questões, seguiremos o percurso descrito a seguir. Em um primeiro momento, discutiremos Shakespeare e diversas localizações culturais por ele ocupadas; abordaremos algumas visões sobre o dramaturgo inglês em relação ao cânone da literatura ocidental, seu elevado capital cultural e as transações que envolvem tal capital, especialmente como ele é acionado/atacado em contextos póscoloniais, bem como traremos alguns dados sobre a presença de Shakespeare no Brasil e na literatura aqui produzida. A seguir, apresentaremos algumas questões teóricas referentes à antropofagia e à paródia, na condição de conceitos que dialogam e que têm o potencial de promover a descolonialidade a partir de uma desobediência epistêmica. Por fim, desenvolveremos articulações entre essas duas seções com/em nossa análise do romance Sonho de uma noite de verão.

\section{Shakespeare e sua(s) localização(ões) cultural(ais)}

Incontestavelmente, Shakespeare é um dos autores mais importantes dentro do campo literário mundial. Sua obra - composta por peças (históricas, cômicas e dramáticas), sonetos e longos poemas narrativos - tem sido substancialmente consumida, estudada, referenciada e adaptada ao longo dos séculos, nos mais diversos contextos nacionais, regionais, locais, pós-coloniais. Além de sua produção literária, a própria figura de Shakespeare tem também recebido grande destaque nos discursos acadêmicos, jornalísticos e artísticos. Nesse sentido, podemos citar as várias biografias sobre o dramaturgo, sua recuperação como personagem em romances (como a narrativa que é objeto de estudo desse artigo) e filmes (a exemplo de Shakespeare Apaixonado), documentários sobre sua vida e obra - muitos deles com propósitos educacionais, polêmicas/teorias da conspiração ${ }^{3}$, etc.

Considerando a grande difusão de Shakespeare pelo mundo, Siobhan Keenan e Dominic Shellard (2016) argumentam que Shakespeare tem um enorme capital cultural, termo cunhado pelo sociólogo francês Pierre Bourdieu que "descreve o social e a estima social auferidas pelos membros da sociedade que detêm 'a competência cultural' para interpretar e entender obras de arte, a exemplo da literatura" ${ }^{4}$ (KEENAN; SHELLARD,

3 Ver, sobre esse tópico, a discussão de Constance Grady (2016) sobre a teoria anti-Stratfordiana, que defende a tese de que a figura histórica William Shakespeare não foi o autor da obra que hoje é a ele associada.

4 Esta e as demais traduções, quando não indicados os tradutores nas referências, são de responsabilidade dos autores do artigo. 


\section{Criação \&}

2016, p. 2). O crítico e teórico estadunidense Harold Bloom certamente é um desses membros da sociedade a que se pode creditar certa competência (certo capital acadêmico) para avaliar Shakespeare e sua obra, o que torna válida uma perscrutação de seus argumentos. No livro $O$ cânone ocidental: os livros e as escola do tempo, por exemplo, Bloom atribui a Shakespeare uma posição central dentro da produção literária no Ocidente. Para o estudioso, Shakespeare está no centro do cânone por superar "todos os outros escritores ocidentais em acuidade cognitiva, energia linguística e poder de invenção" (BLOOM, 1995, p. 52). Em outra afirmação ainda mais taxativa, lemos: "Literatura é, com a máxima certeza: Shakespeare é o Cânone. Ele estabelece o padrão e os limites da literatura" (BLOOM, 1995, p. 55).

O fato de propor a estruturação de um Cânone (com inicial maiúscula) e a não inclusão de nenhum escritor brasileiro, por exemplo, já são bastante iluminadores do local de onde Bloom escreve e de seu posicionamento político-ideológico. De qualquer forma, devemos concordar com o estudioso e sua afirmação de que Shakespeare é tido como um dos símbolos do que se convencionou como "alta cultura" ou "alta literatura". Para além disso, Douglas Lanier (2002, p. 3) chama a atenção para a forte presença do dramaturgo inglês também em meio às práticas do que se considera cultura de massa:

Cinema, televisão, rádio, literatura de massa, histórias em quadrinhos, brinquedos, jogos de computador, pornografia: em quase qualquer categoria imaginável da cultura popular pode-se encontrar exemplos de alusões ou de adaptações shakespearianas.

A produção, o consumo e a circulação em grande escala de produtos midiáticos (e aqui incluímos a própria literatura e as performances teatrais) que envolvem diretamente Shakespeare e sua obra, em ambos os níveis da alta cultura e da cultura popular, são em grande medida responsáveis pelo elevado capital cultural do escritor inglês. De fato, tal capital - que envolve valores culturais/literários e econômicos - é tão vasto que alguns teóricos mencionam que Shakespeare já pode ser visto como significante icônico (LANIER, 2006) e ícone cultural (KEENAN; SHELLARD, 2016), além de como propriamente uma marca (KEENAN; SHELLARD, 2016; MASSAI, 2005) ou um logo ${ }^{5}$ (MASSAI, 2005; MONTIRONI, 2012).

O caso das recuperações intertextuais (paródias, alusões, adaptações) da obra de Shakespeare é bastante revelador das práticas de transferência de capital que circundam o autor e sua obra. Para Keenan e Shellard (2016, p. 5), tais práticas "confiam no 'capital cultural' que tem sido associado a Shakespeare [...] e/ou em associações culturais específicas que Shakespeare tem acumulado ao longo do tempo" (KEENAN; SHELLAR, 2016, p. 5). Diversos podem ser os objetivos de escritores, pintores, cineastas, entre outros, que se dispõem a dialogar intertextualmente com Shakespeare e seu capital

5 Montironi (2012) argumenta a existência de uma 'Shakespeare logo', comparável à Nike ou à Coca-Cola. 


\section{Criação \&}

cultural: eles podem estar em busca de lucros financeiros - Linda Hutcheon (2013) argumenta, por exemplo, que adaptar Shakespeare é uma aposta segura em termos de retorno econômico -, de prestar uma homenagem ao dramaturgo, de desafiar a ideia de "Cânone" apresentada acima, de repensar/iluminar a contemporaneidade a partir dos textos e personagens renascentistas, etc. De fato, os objetivos são quase tão numerosos quanto as práticas intertextuais: a fim de se perceber qual a intenção que subjaz ao processo adaptativo, cada paródia ou adaptação precisa ser individualmente analisada.

Nas últimas décadas, é perceptível um aumento no número de recuperações intertextuais que envolvem a figura de Shakespeare e sua obra, nos mais diversos contextos nacionais, regionais e locais - recuperações, pois, que promovem uma hibridização entre Shakespeare e diversas outras culturas (LANIER, 2006). Além das traduções e montagens dos textos dramáticos, essas várias adaptações contribuem substancialmente para a intensa sobrevida cultural de Shakespeare, sobrevida marcada pelas "formas com que as obras, a vida e a imagem de Shakespeare têm sido usadas, depredadas, remodeladas e revistas por [distintas] gerações e culturas" (LANIER, 2006, p. 229).

Esse tipo de engajamento com o texto shakespeariano, diz-nos Martin Orkin (2005, p. 1), "sempre envolve [...] encontros ou choques culturais"; somos todos, afinal, leitores historicamente situados, o que faz com que nossas leituras dependam de nosso contexto espaçotemporal, idade, gênero, repertório de leituras, etc. Dessa forma, podemos argumentar que Shakespeare - direta ou indiretamente, via práticas intertextuais -, ao chegar em novos lugares e alcançar novos leitores, acaba por alcançar também novas possibilidades de leitura e interpretação. E essas novas possibilidades são especialmente relevantes quando consideramos que Shakespeare, no século XXI, "não é um monólito único, mas sim uma multidão de construtos autorais que evoluem continuamente" (OLSSON, 2013, p. 29).

Já que Shakespeare, assim, pode ser melhor entendido como "a soma das respostas críticas e criativas que são suscitadas por suas obras” (MASSAI, 2005, p. 6), torna-se ainda mais relevante a observação de respostas que foram criadas fora do eixo Europa-América do Norte, pois elas podem "alargar, desafiar e modificar nosso entendimento do que é 'Shakespeare"' (MASSAI, 2005, p. 6). Em contextos locais especialmente na América Latina, África e Ásia -, Shakespeare é confrontado com o que é epistemologicamente corrente naquele lugar, com diferentes posicionamentos e lutas institucionais, com conhecimentos e ideologias particulares que lá são valorizadas (ORKIN, 2005, p. 2).

Em contextos pós-coloniais, é interessante perceber como, na condição de parte da "herança" colonial, Shakespeare é ressignificado. Não podemos esquecer, nesse sentido, que a própria difusão global de Shakespeare é devedora do colonialismo, especialmente através dos sistemas educacionais das colônias que compuseram o Império Britânico. Lanier (2006, p. 239), referindo-se aos estudos culturais shakespearianos que são informados por teorias pós-coloniais, elenca uma série de questionamentos que são desenvolvidos e repercutem nessa área, a saber: 


\section{$24^{\text {cratacaio }}$}

que tipos de encontros culturais e ideológicos essas obras representam? Esses encontros culturais entre Shakespeare e uma "outra" tradição são contestatórios, mutuamente iluminadores ou legitimadores, são uma forma de imperialismo cultural ou uma autoafirmação nacional, uma mistura pósmoderna de estilos ou evidências da universalidade de Shakespeare? [...] Os significados desses híbridos culturais são particularmente sensíveis às condições específicas de sua produção e recepção?

A mais representativa recuperação intertextual e pós-colonial da obra de Shakespeare se deu com a peça $A$ Tempestade, trama em que Próspero, duque de Milão, exilado, atraca na ilha ficcional na qual o único habitante era Caliban. Este, o nativo "selvagem", é "colonizado" pelo europeu: aprende a língua de Próspero e é submetido a um regime de trabalho forçado. De acordo com Susanne Klengel (2000, p. 58-59), especialmente no Caribe, após o final da Segunda Guerra Mundial, com o início dos movimentos de independência, a figura de Caliban passou a ser acionada como um símbolo dos povos oprimidos e colonizados. O personagem se torna representativo do rebelde anticolonial, que se torna consciente de sua condição de colonizado e que passa a confrontar o colonialismo cultural e político da metrópole, do Norte industrializado.

Para além de $A$ Tempestade (que tematiza mais diretamente a questão da colonização), incursões intertextuais e interculturais, em contextos pós-coloniais, que fazem dialogar Shakespeare e culturas e saberes locais, têm o potencial de trazer à tona "perturbações, complicações ou embates epistemológicos" (ORKIN, 2005, p. 2). Perturbar, complicar, combater e embaraçar Shakespeare e sua obra pode significar, por tabela, ir de encontro também às culturas/sociedades/nações que apadrinham os discursos (colonizadores) que advogam pela posição hipercentral de Shakespeare, como núcleo incontestável de um Cânone ocidental. Convém ressaltar, porém, que a via contestadora ou embargadora é sempre de mão dupla. Como apresenta Orkin (2005, p. 4), "encontros culturais desestabilizam e desafiam, para todos os participantes, certezas epistemológicas. Conhecimentos locais que residem para além dessas certezas irão sempre, ao menos, enquadrá-las, e, em seu melhor, iluminá-las ou ajustá-las provocativamente".

Apesar de não ter sido uma colônia inglesa, não ter feito parte do Império Britânico e não falar a língua dessa potência colonizadora, o Brasil se encaixa no extremo sul do planeta, tendo sofrido e ainda sofrendo influência direta da colonialidade anglófona. No campo da literatura, precisamos apenas observar a enorme quantidade de obras à venda em livrarias que são traduções de obras originalmente escritas em inglês. É bastante interessante, assim, buscar perceber como Shakespeare - apontado por muitos como "o" autor inglês - e sua obra têm sido recebidos e reescritos em nosso país.

Aimara Resende da Cunha (2002) apresenta um interessante panorama de como Shakespeare tem sido apropriado e adaptado no Brasil. Para a estudiosa, destacam-se duas correntes: a primeira, simbolizada pelos primeiros dramaturgos a encenarem peças 


\section{Criação \&}

shakespearianas no século XIX, por Gonçalves Dias (e sua releitura melodramática e "portuguesa" de Otelo), caracteriza-se por uma posição extremamente respeitosa pela obra do Bardo, através de uma assimilação passiva, que legitimou de forma acrítica a centralidade de Shakespeare; a segunda corrente, por sua vez, ao (re)ler Shakespeare criticamente, configura uma substancial prática de diálogos interculturais - Shakespeare pode até mesmo ser assimilado, porém não sem antes ser condimentado com temperos brasileiros, a fim de ser devorado e digerido. Como expoentes dessa segunda corrente, Resende aponta Machado de Assis, Augusto Boal e Gabriel Vilela.

Sobre Shakespeare, globalização e recuperações pós-coloniais, Lanier (2006, p. 242) faz o seguinte questionamento: "Quais são os caminhos de difusão, modos de afiliação, ansiedades da influência e hierarquias implícitas para todos esses Shakespeares globais?". Com a criação de seu Shakespeare brasileiro e baiano, entendemos que Falcão se filia à segunda corrente mencionada acima, através de um caminho de difusão, modo de afiliação e ansiedade da influência tipicamente brasileiros, tipicamente antropofágicos, interculturais e paródicos.

\section{Antropofagia, paródia e desobediência epistêmica}

Credita-se a Oswald de Andrade (2011a, 2011b) e a dois importantes manifestos por ele escritos, "Manifesto Pau Brasil", em 1924, e, principalmente, "Manifesto Antropófago", que data de 1928, o impulso antropofágico que caracterizou a literatura modernista brasileira e que ainda repercute nas produções ficcionais contemporâneas, como atestam os três romances da Coleção Devorando Shakespeare. Oswald de Andrade foi um dos mais destacados pensadores (e polemistas) do movimento modernista brasileiro nas décadas de 1920 e 1930. Junto a Mario de Andrade, Tarsila do Amaral e outros intelectuais e artistas, Oswald de Andrade promoveu uma defesa da autonomia da cultura, da literatura e da arte brasileiras, a partir de um modo de expressão próprio, ou ainda de uma epistemologia nacional.

Como um projeto tipicamente brasileiro, porém, não poderia haver uma recusa ao outro e/ou à miscigenação - a própria constituição do país é em grande medida devedora à mistura entre os povos indígenas, europeus e africanos. Não temos, assim, em seus escritos, uma negação do outro, do estrangeiro; temos, sim, uma negação de práticas de assimilação passivas e acríticas do outro, principalmente quando esse outro é representado pelo homem branco europeu, símbolo dos ideais da Modernidade e do Colonialismo.

Tais ideias podem ser identificadas nos dois manifestos mencionados acima. No "Manifesto da Poesia Pau-Brasil", lê-se: "O Brasil profiteur. O Brasil doutor. E a consciência da primeira construção brasileira no movimento de reconstrução geral. Poesia Pau-Brasil" (ANDRADE, 2011a, p. 22-24) e "Nenhuma fórmula para a contemporânea expressão do mundo. Ver com olhos livres (ANDRADE, 2011a, p. 24, ênfase original). Já no "Manifesto Antropófago", encontramos as seguintes passagens: "Contra todos os 


\section{Criação \&}

importadores de consciência enlatada. A existência palpável da vida" (ANDRADE, 2011b, p. 27) e "Contra o mundo reversível e as ideias objetivadas. Cadaverizadas. $O$ stop do pensamento que é dinâmico. O indivíduo vítima do sistema. Fonte das injustiças clássicas" (ANDRADE, 2011b, p. 28).

Especialmente a noção de antropofagia, tal como articulada por Andrade, tem muito a informar sobre as práticas artísticas/intertextuais/pós-coloniais sobre as quais temos discutido. Referimo-nos, mais especificamente, à noção de antropofagia cultural como uma estratégia criativa que se propõe a devorar textualidades e culturas estrangeiras, "fazendo o antigo elemento não nativo se unir àquilo que é substancialmente nacional, regional, autóctone, fazendo nascer um mestiço que irá ostensivamente chamar atenção para suas marcas de Brasilidade" (RESENDE, 2002, p. 16-17).

A escolha pelo verbo "devorar", na coleção Devorando Shakespeare, articula os três romances à prática antropofágica de devoração do estrangeiro, no caso, Shakespeare - suas obras, sua cultura e sua figura histórica. Tal como apresentada por Oswald de Andrade, em seus manifestos, podemos entender a devoração do outro como a instituição da negociação intercultural como exercício preferencial. Isso significa dizer que a devoração vai além de um nível textual, pois o texto não pode ser entendido como nascendo no vácuo; ele traz em si marcas de sua gênese, de sua circulação e de sua sobrevida culturais. Nesse sentido, concordamos com Patrice Pavis (2008, p. 2, ênfase original) e seu argumento de que:

O modelo da intertextualidade [...] cede seu lugar ao da interculturalidade. Com efeito, não basta mais descrever as relações dos textos [...], entender o seu funcionamento interno; é preciso da mesma forma, e acima de tudo, compreender a sua inserção nos contextos e culturas, bem como analisar a produção cultural que resulta desses deslocamentos imprevistos. $O$ termo interculturalismo parece-nos adequado [...] para nos darmos conta da dialética de trocas dos [...] procedimentos entre as culturas.

De acordo com Pavis (2008), os processos de trocas, diálogos ou transferências culturais, nos quais podemos incluir a devoração antropofágica, não ocorrem de forma passiva ou automática. Pelo contrário, tais processos são ativamente controlados pela cultura de chegada - em nosso caso, a brasileira -, que busca no outro respostas para necessidades e problemas concretos. De fato, há diversos mecanismos que medeiam, na forma de ênfases e filtros, o processo de transferência intercultural, em função dos interesses e propósitos da cultura de chegada. Em termos semelhantes, Marcel Alvaro de Amorim (2018, p. 10) propõe a noção de devoração transcultural como o processo que, levando em conta os diálogos entre textos e culturas,

considera os elementos do texto de partida, mas, ao mesmo tempo, os utiliza criativamente, renovando-os, desconstruindo-os, reconstruindo-os e 


\section{Criação \&}

os inserindo mutuamente na tradição e nas culturas de chegada em uma relação com as culturas de partida.

$\mathrm{Na}$ análise que segue, buscaremos responder: afinal, no Brasil do século XXI, como e por que devorar Shakespeare? Por ora, convém chamar atenção para o fato de que a devoração intertextual e intercultural, realizada por Falcão, traz em si muitos traços de práticas artísticas contemporâneas que podem ser vistas através do prisma da paródia e da ironia. De fato, a releitura de Shakespeare feita pela escritora brasileira parece-nos uma forma de imitação criativa, caracterizada por uma inversão irônica, ou, "noutra formulação, repetição com distância crítica, que marca a diferença em vez da semelhança" - que é a definição da teórica canadense Linda Hutcheon $(1989$, p. 17) para a paródia.

Aprofundando sua discussão sobre a paródia, Hutcheon chama a atenção para a própria etimologia da palavra, que vem do grego parodia, sendo uma união de para e odos:

A natureza textual ou discursiva da paródia [...] é evidente no elemento odos da palavra, que significa canto. O prefixo para tem dois significados, sendo geralmente mencionado apenas um deles - o de "contra" ou "oposição". Desta forma, a paródia torna-se uma oposição ou contraste entre textos. Este é, presumivelmente, o ponto de partida formal para a componente de ridículo pragmática habitual da definição [...]. No entanto, para em grego também pode significar "ao lado de" e, portanto, existe uma sugestão de um acordo ou intimidade, em vez de contraste (HUTCHEON, 1989, p. 47-48, ênfase original).

Para que possamos compreender os diferentes funcionamentos da paródia, dessa forma, ambos os dados de "contra" e "ao lado de" devem ser levados em consideração no contato com textos paródicos e seus "alvos". Além disso, não é possível antecipar qual será a relação entre texto paródico e autor/texto/gênero/convenção parodiado/a: "a postura da paródia em relação a seu alvo é frequentemente ambivalente, podendo ir da degradação e da zombaria a uma admiração respeitosa" (KORKUT, 2005, p. 1).

A postura ambivalente é um ponto em comum importante entre a antropofagia e a paródia. Se um texto paródico pode abarcar em si simultaneamente o desejo de zombar e homenagear, a antropofagia, diferentemente do canibalismo, envolve o elemento de respeito pela figura do outro, que será incorporado via devoração e digestão - conforme o próprio Oswald de Andrade (2009, p. 66), "[...] nunca se soube de homem que deglutisse o que the desagradasse" (ANDRADE, 2009, p. 66).

Ambos os procedimentos criativos, dessa forma, facilitam a produção de uma literatura que habita o espaço ambíguo e ambivalente do entre-lugar - espaço esse que recebe bastante atenção em discussões no âmbito das teorias pós-coloniais. Homi Bhabha (1998), por exemplo, trata o entre-lugar como o espaço da incerteza, da 
indecidibilidade, como local a partir de onde a hibridização e os contágios interculturais podem ser entendidos como uma contranarrativa anticolonial, como uma forma de crítica ao discursos coloniais - e, por conseguinte, à própria ideia de cânone literário. Esses espaços ambivalentes do entre-lugar têm marcado o discurso brasileiro e latino americano nas últimas décadas, de acordo com Silviano Santiago (2000). Para o teórico, "entre o sacrifício e o jogo, entre a prisão e transgressão, entre a submissão ao código e a agressão, entre a obediência e a rebelião, entre a assimilação e a expressão [...] se realiza o ritual antropófago da literatura latino-americana" (SANTIAGO, 2000, p. 26). Antropófago e paródico, acrescentaríamos.

Antropofagia e paródia, dessa forma, como práticas de incorporação e transformação irônicas e potencialmente subversivas, são capazes tanto de "apropriação quanto de expropriação, desierarquização, desconstrução" (CAMPOS, 2006, p. 234-235). Ou ainda, de acordo com Klengel (2000, p. 61),

A paródia canibal, o desafio aos sistemas simbólicos convencionais, aos atributos e hierarquias culturais, levada a cabo pela devoração e carnavalização de uma herança cultural europeia, sem qualquer respeito por ordens cronológicas ou genealógicas dos textos, fatos e teorias, juntase a outras estratégias pós-modernas de desierarquização, em uma eclética revisão do passado cultural.

A releitura de uma celebrada peça shakespeariana, bem como da figura do próprio autor inglês, através do prisma da antropofagia e da paródia, significa uma desestabilização de uma série de discursos que continuamente reafirmam política e ideologicamente a centralidade de Shakespeare - e, portanto, da literatura anglófona e das próprias língua e cultura inglesas. Significa, de forma crítica, interrogar e enquadrar tais discursos entre aspas - marcando-os como historicamente situados, interessados e não-neutros. Significa cometer um ato de desobediência epistêmica.

Como desobediência epistêmica, acompanhamos o pensamento do teórico Walter Mignolo (2008), para quem a desobediência epistêmica é um passo necessário dentro de um projeto maior de descolonização. Tal projeto significa uma desvinculação dos discursos eurocêntricos que marcaram a Modernidade e, em última instância, também a colonização: "A colonização, em outras palavras, é constitutiva da modernidade - não há modernidade sem colonização" (MIGNOLO, 2011, p. 3). Em The Darker side of Western Modernity, Mignolo (2011) advoga pela necessidade de apreender, compreender, denunciar e combater em termos "descolonizadores" os valores e conceitos legados pela Modernidade e pela colonização. Mignolo faz a escolha do termo descolonial, ao invés do comumente utilizado pós-colonial, a fim de demarcar mais claramente as implicações de crítica, ruptura, negação e desconstrução em relação à colonização. Para o pensador, o eurocentrismo que marcou a colonização espacial também marcou uma colonização epistêmica - ele cita Kant como exemplo, quando este estabelece, através da 


\section{$244_{\text {caracabo }}^{\text {cal }}$}

racionalidade e do discurso científico correntes, uma relação entre os habitantes dos continentes e a cor de suas peles.

Para combater a colonização e o racismo epistêmicos, Mignolo, que entende a dificuldade de se pensar fora do legado ocidental e de sua hegemonia epistêmica, apresenta a saída da opção descolonial. Tal opção implica "pensar a partir da exterioridade e em uma posição epistêmica subalterna vis-à-vis à hegemonia epistêmica que cria, constrói, erige um exterior a fim de assegurar sua interioridade" (MIGNOLO, 2008, p. 305). Também afirma que o projeto "[d]escolonial implica pensar a partir das línguas e das categorias de pensamento não incluídas nos fundamentos dos pensamentos ocidentais" (MIGNOLO, 2008, p. 306). Significa ainda ter como norte (ou como Sul, se preferirmos) a noção de interculturalidade como modo de compreensão do mundo e das relações humanas, que traz consigo a noção de "interepistemologia, um diálogo intenso que é o diálogo do futuro entre a cosmologia não ocidental [...] e ocidental" (MIGNOLO, 2008, p. 316).

A seguir, discutiremos a releitura de Adriana Falcão de Sonho de uma noite de verão e sua recuperação intertextual, intercultural, antropofágica, paródica e desobediente da figura do dramaturgo e poeta inglês William Shakespeare.

\section{Seu Biu}

Em sua releitura de uma das peças mais conhecidas de Shakespeare, Sonho de uma noite de verão, na forma de um romance - que recebeu o mesmo título da peça -, Adriana Falcão transporta para o Brasil, mais especificamente para a Bahia, durante a festa de carnaval em Salvador, os acontecimentos que envolvem o casamento do Duque Teseu com a Rainha das Amazonas Hipólita, os desencontros amorosos entre Hérmia, Helena, Lisandro e Demétrio, uma trupe teatral que irá encenar uma peça durante as celebrações do casamento e o mundo fantástico das fadas e dos elfos. As sensações de sonho e de vale tudo que caracterizam as idas e vindas do texto shakespeariano encontraram local ideal para serem atualizadas, pois a trama criada por Falcão, ao ser ambientada na festa de carnaval de quatro dias na capital baiana, propicia em igual medida a impressão de que tudo é possível.

As descrições da festa de Carnaval em Salvador são um ponto de partida para os entrelaçamentos culturais ou atualização antropofágica de Shakespeare e sua obra em contexto brasileiro. Diversos elementos da cultura brasileira - e mais especificamente da cultura baiana - são acionados em relação a essa festa popular. Assim que chegaram à Terra, por ordem de Hera, a fim de averiguar a existência de humanos, os seres mágicos se depararam com o carnaval já em plena marcha nas ruas de Salvador:

Ali embaixo, o povo era separado em grupos, uns menores, outros gigantes. 


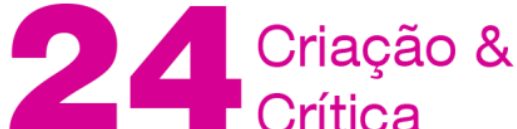

Alguns eram destaques e pulavam no topo de carros cantantes que eram conhecidos como "trios elétricos".

Muitos, numa procissão desvairada, seguiam os tais trios.

Dos muito que seguiam os trios, alguns usavam uma espécie de uniforme, chamado de abadá, que Ihes dava direito a ficarem cercados por cordões de isolamento, protegidos, talvez, de monstros perversos (FALCÃO, 2007, p. 27-28).

A utilização do ponto de vista dos seres mágicos para a descrição da festa do carnaval de rua soteropolitano funciona como um efeito de estranhamento reverso na prática antropofágica, com a cultura do outro iluminando a nossa cultura. A exclusão social e o uso de uniformes/abadás, pois, são ironicamente recuperados a partir do olhar estrangeiro, aquele dos seres mágicos, atuando como marcas de incongruência entre práticas elitistas e uma festa eminentemente popular, uma "procissão desvairada".

Outro momento de crítica social às culturas e práticas locais ocorre em relação ao mundo da política e a casamentos arranjados:

Como não tinha irmãos que dividissem com ela essa responsabilidade, a moça terminava sendo o único instrumento familiar que o pai poderia utilizar a seu favor em sua "luta pelos direitos do povo", que era como ele chamava sua vontade de ganhar a eleição.

- Se ele luta pelos direitos do povo, não deveria lutar também pelo direito da filha de namorar quem quiser? - estranhou Mariposa.

- Vai ver ela não é "povo".

- Será que só é "povo" quem é pobre? (FALCÃO, 2007, p. 42).

Mais uma vez, a dramatização da visão do estrangeiro sobre práticas correntes locais foi capaz de jogar luz sobre o caráter escuso de muitas ações que rodeiam o universo da política - e, principalmente, dos políticos. Convém ressaltar que questões políticas dessa ordem não são tratadas na comédia shakespeariana; são, pois, parte do processo de atualização paródico e antropofágico levado a cabo por Falcão. Com isso, temos já um primeiro indício de que o exercício de atualização desenvolvido pela escritora brasileira segue o caminho da interculturalidade como modelo antropofágico, pois temos uma atualização em relação direta e dialógica com o outro, que busca especialmente a mudança na própria identidade (CASTRO, 2002).

Além desses dois exemplos, outros elementos da cultura local são trazidos para o primeiro plano através desse olhar de estranhamento - da visão com olhos livres, parafraseando Oswald de Andrade. A troca de partidos políticos (e rápido abandono de uma suposta ideologia política) por parte dos personagens é bastante significativa nesse sentido. Ou ainda a ironia jogada sobre o trato diferenciado que os policiais militares (PMs) oferecem a Seu Biu quando este se apresenta como William Shakespeare: "Ainda bem que policial geralmente respeita nome americano" (FALCÃO, 2007, p. 105). 


\section{Criação \&}

Outras referências e recuperações culturais ainda são indicadoras do caráter intercultural da narrativa de Falcão, a exemplo de Helena e seu carnaval religioso: "Pediu forças à Mãe Terra. Recitou um mantra para Krishna. Derramou solicitações a Cupido. Jogou seu colar para lemanjá. Fez o sinal da cruz. Evocou o arrebatamento para ajudá-la" (FALCÃO, 2007, p. 52); e das fadas e sua mistura de gêneros musicais: "As fadinhas se puseram a entoar uma fantástica cantiga povoada por 'bois da cara preta', 'Tutankamons', e 'rouxinóis', talvez a primeira e quem sabe a única manifestação musical em estilo nanaaxé-lullaby de que se tem notícia" (FALCÃO, 2007, p. 73, ênfase original).

Em meio às atualizações interculturais, destacam-se especialmente aquelas que se referem à figura do próprio dramaturgo e poeta inglês William Shakespeare. Convém ressaltar, nesse sentido, que, na condição de escritora de uma obra que faz parte de uma coleção intitulada Devorando Shakespeare, Falcão foi a única a oferecer ao autor renascentista a condição de personagem em sua trama. E isso se dá especialmente em relação a Seu Biu, o dono do bar Matagal do Duque, espaço em que transcorrem diversas ações do romance. Antes, porém, de Seu Biu de fato "entrar em cena" (o que ocorre aproximadamente na metade da narrativa, quando ele é acionado para tentar solucionar os conflitos e desencontros amorosos causados por Puck), algumas menções a Shakespeare já haviam sido feitas.

No início do romance, por exemplo, quando os seres mágicos ainda estavam no Panteão dos Deuses, de partida para a Terra a fim de averiguar a existência de humanos, Shakespeare já é apresentado como o Deus das Histórias:

Até Shakespeare, o Deus das Histórias, que não era dado a badalações, resolveu aparecer. Quando viu os seis personagens enfileirados, em posição de partida, orgulhosos de si mesmos, pensou: "Isso vai dar problema". Repensou: "Sem problema, qual seria a graça?" Então sorriu (FALCÃO, 2007, p. 21-22).

A representação de Shakespeare na condição de divino, como o Deus das Histórias, o coloca em uma posição bastante elevada; a menção contínua ao dado divino/sobrenatural do dramaturgo, ao longo do romance, contribui para uma imagem sobre-humana de Shakespeare e de seu potencial para criar histórias.

Tal imagem divina, que será mais substancialmente subvertida especialmente a partir do Shakespeare brasileiro, Seu Biu, já começa a ser enfraquecida antes mesmo que este apareça como personagem na trama. Como uma antecipação a todos os conflitos e confusões que caracterizam as linhas de enredo dos outros personagens, lemos o seguinte trecho, a partir da narração em terceira pessoa:

O imbróglio que assistiram em seguida possivelmente foi traçado por algum inspirado autor de destinos, maluco que era, um tipo de encontros e desencontros bem característico do planeta Terra, dessas tramas que 


\section{Criação \&}

depois viram até comédias e podem ser representadas por quem quer que deseje comentar a estranha condição humana (FALCÃO, 2007, p. 41).

Como pontos positivos da representação de Shakespeare, temos as indicações de um alto grau de inspiração e o fato de que ele é "autor de destinos", elementos compatíveis com a caracterização de Shakespeare como o Deus da Histórias. Por outro lado, já temos um interessante dado que vai em direção a essa atmosfera celestial: se era inspirado e autor de destinos, Shakespeare também era um "maluco", genial criador de encontros e desencontros, de conflitos: "Há que se reconhecer que fosse lá quem fosse que estivesse tramando toda essa história, era portador de uma cabeça inventiva que não desperdiçava uma única oportunidade de fazer render conflito" (FALCÃO, 2007, p. 76).

Shakespeare e sua condição celestial ganham contornos menos claros e uniformes assim que ele passa a ser relacionado a Seu Biu:

Quem olhasse para Seu Biu ali, atrás do balcão, vendendo bebidas e tiragostos, nunca imaginaria que aquele senhor monossilábico pudesse se transformar em outro quando estava alcoolizado.

Bastava uma "branquinha", que era como ele chamava sua cachaça predileta, e o humilde e simplório velhinho virava um verdadeiro gênio. Filosofava, vomitava erudições e escrevia textos [...]. Nessas horas, pedia que the chamassem de "Bill", com dois "eles", por uma questão de respeito. [...]

Todo Carnaval, Seu Biu se fantasiava de poeta do século XVI e tomava todas. Era então que incorporava o seu pai de santo predileto e se orgulhava de ser experto em resolver questões sentimentais (FALCÃO, 2007, p. 60-61).

As relações entre Shakespeare e Seu Biu podem ser percebidas desde seus nomes: Biu (apelido comum no Nordeste para aqueles que se chamam Severino) se transforma em Bill (um dos apelidos correntes para o nome William, em contexto anglófono), quando há a incorporação do espírito do pai de santo/Deus das Histórias/Shakespeare. O dado da incorporação e a menção a um pai de santo, característicos de religiões de matriz africana, como a umbanda e o candomblé, que são especialmente fortes na Bahia e em Salvador, quando conectados à cachaça, tornam ainda mais complexa a representação de Shakespeare. Se, por um lado, a incorporação ainda lida com o sagrado, por ocorrerem em decorrência do consumo excessivo da "branquinha" temos um claro rebaixamento, uma inversão do alto com o baixo que caracteriza a literatura carnavalesca (BAKHTIN, 1987). A ambivalência, nesse sentido, prevalece: se, por um lado, temos a cachaça, por outro, temos a genialidade que é dela decorrente.

Quando Seu Biu/William Shakespeare se apresenta para Puck a fim de ajudá-lo a solucionar os conflitos, esse não acredita imediatamente se tratar do Bardo de Stratfordupon-Avon. Durante e após algumas tentativas fracassadas em que Puck tentou averiguar 


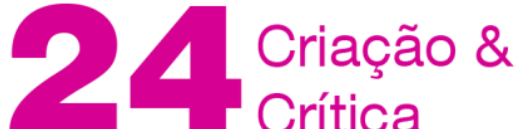

a identidade de Shakespeare - pedindo para que ele complemente o final de célebres frases como "Ser ou não ser...?" -, ele profere uma série de ofensas, entre elas falsário, embusteiro, salafrário, biriteiro, dramaturgo disfarçado, vigarista e impostor, que contribuem para o rebaixamento da figura de Shakespeare, sua profanação.

Após resolvido o mal-entendido inicial, Seu Biu/Shakespeare aceita ajudar Puck na resolução dos conflitos entre Lisandro, Demétrio, Helena e Hérmia. É então que lemos o seguinte diálogo:

- Uma coisa de cada vez, meu caro Puck. Deixa eu raciocinar um pouquinho? Vou ali buscar outra lapada para ver se eu me inspiro.

E tome cana, e pensamento, e mais cana, e o tempo ia passando, e Puck já estava inquieto.

- Daqui que você arranje um jeito de resolver os problemas, Lisandro e Demétrio já se trucidaram!

- O jeito eu já arranjei. Estou pensando é no estilo.

- Não temos tempo para isso.

- A forma, em alguns casos, pode até inspirar o conteúdo da obra.

- Vai da forma que for e já está ótimo.

- É que eu não queria me utilizar do recurso da magia.

- Por que não?

- Muito fácil. Mais rico resolver tudo no raciocínio.

- Conversa fiada de quem não sabe o que fazer e quer dar uma desculpa.

- Precisamos organizar os pares.

- Isso.

- E fazer com que os amantes pensem que tudo isso foi um sonho (FALCÃO, 2007, p. 103-104).

Na passagem, temos colocados como polos opostos dois modos de resolução de conflitos, a magia e o raciocínio, respectivamente apontados pelos discursos hegemônicos eurocêntricos como uma conduta antiga/primitiva e uma conduta moderna/científica/europeia. Levando isso em consideração, convém ressaltar a observação de Carlos Rincón (2011, p. 552), para quem a antropofagia, como uma prática de assimilação simbólica pós-colonial, coloca em questão o colonialismo e o discurso colonial - especialmente suas fixações binárias, como o civilizado/o bárbaro, o Mesmo/o Outro, a ciência/a magia. Podemos perceber esse movimento contestador também na narrativa de Falcão: embora nesse momento Seu Biu/Shakespeare não tenha feito uso da magia - como fará no final, ao realizar um poderoso trabalho espiritual para que os seres sobrenaturais se tornem mortais e possam ficar na Terra -, a solução encontrada, mesmo que através do raciocínio, em muito difere da razão moderna e europeia. Como solução, pois, Seu Biu/Shakespeare chamou os quatro jovens e com eles bebeu várias garrafas de cachaça, a fim de que quando acordassem não se lembrassem de nada, como resultado de uma amnésia alcoólica. 


\section{Criação \&}

A partir da devoração antropofágica e da reconstrução paródica da figura de William Shakespeare feita por Falcão, temos como resultado uma prática irônica e carnavalizada, em que a ambivalência em torno do poeta e dramaturgo inglês não se resolve. E acreditamos que essa não resolução, essa permanente tensão, é um dos grandes êxitos de Falcão em seu romance: através de sua narrativa desobediente, que ora coloca Shakespeare na posição celestial de gênio, ora coloca-o na de beberrão terreno - por vezes sobrepondo ambas as representações e não sendo um caso de ou/ou, mas sim de e/ambos -, a escritora brasileira demonstra que um dos primeiros passos para a descolonização epistêmica é o entendimento de que o pensamento é dialógico, dialético e interconectado.

Shakespeare, assim, por vezes apontado como símbolo da Inglaterra ou do Norte Ocidental Moderna/o e Colonialista e dos valores e ideologias lá correntes, acaba se mostrando também como um potente remédio ou antídoto do Sul, capaz de antropofágica e parodicamente subverter discursos hegemônicos. No Brasil contemporâneo, ao ser ainda articulado à festa popular do carnaval, à bebida, à magia e à inventividade, a mensagem passada se torna ainda mais poderosa à medida que Shakespeare se torna ainda mais atraente, mais facilmente comestível.

\section{Considerações finais}

Com Sonho de uma noite de verão, Adriana Falcão passa a integrar um grupo de escritores latino-americanos, africanos e asiáticos que, quando se encontraram frente a Shakespeare e a sua obra, optaram pela via descolonial. Especificamente no Brasil, Falcão se une a escritores que fizeram uso da antropofagia e de outras estratégias criativas correlatas no processo de devoração intercultural do dramaturgo inglês: "citações para reforçar temas; [...] apropriações subversivas, contrapontos intertextuais, 'Shakespeares' ambivalentes. Transformado, contaminado, o "Bardo" parece e fala como brasileiro. Tabu virou totem" (RESENDE, 2002, p. 17).

Através de uma prática antropofágica, paródica, desobediente e descolonial, Falcão demonstrou ser possível realizar a devoração do outro e de sua cultura - mesmo este outro sendo entendido e continuamente apontado como central e hegemônico - sem necessariamente fazer com que a cultura devoradora recaia para uma posição de inferioridade ou de subalternidade. Pelo contrário: em Sonho de uma noite de verão, a cultura brasileira é representada como complexa, criativa, irreverente, irônica e desobediente.

Se os Estudos Shakespearianos, nas últimas décadas, sofreram mudanças consideráveis, alargando suas possibilidades analíticas para abarcar as perspectivas do Sul, locais e pós-coloniais, nós podemos dizer que isso fez com que o próprio Shakespeare também mudasse - ou ao menos argumentar que se alterou o nosso entendimento sobre o escritor e suas possibilidades de (res)significação. E que esse processo intertextual e intercultural possa continuar a ocorrer, com Shakespeare sendo 


\section{$244^{\text {Cratacá o \& }}$}

colocado para falar em línguas e sotaques não antes imaginados. Inclusive o português brasileiro, nordestino, baiano.

\section{Referências}

ANDRADE, O. Os dentes do dragão. São Paulo: Globo, 2009.

"Manifesto da Poesia Pau-Brasil". In: ROCHA, J. C. de C.; RUFFINELLI, J. (orgs.). Antropofagia hoje?: Oswald de Andrade em cena. São Paulo: É Realizações, 2011a, p. 21-25.

"Manifesto Antropófago". In: ROCHA, J. C. de C.; RUFFINELLI, J. (orgs.). Antropofagia hoje?: Oswald de Andrade em cena. São Paulo: É Realizações, 2011b, p. 27-31. BAKHTIN, M. A cultura popular na Idade Média e no Renascimento: o contexto de François Rabelais. Trad. Yara F. Vieira. São Paulo: Hucitec; Brasília: Ed. da Universidade de Brasília, 1987.

BHABHA, H. O local da cultura. Trad. Myriam Ávila, Eliana Lourenço de Lima Reis e Gláucia Renate Gonçalves. Belo Horizonte: Editora UFMG, 1998.

BLOOM, H. O cânone ocidental: os livros e a escola do tempo. Trad. Marcos Santarrita. Rio de Janeiro: Objetiva, 1995.

CAMPOS, H. Metalinguagem \& outras metas: ensaios de teoria e crítica literária. 4. ed. São Paulo: Perspectiva, 2006.

CASTRO, E. V. A inconstância da alma selvagem. São Paulo: Cosac \& Naify, 2002.

FALCÃO, A. Sonho de uma noite de verão. Rio de Janeiro: Objetiva, 2007.

FURTADO, J. Trabalhos de amor perdidos. Rio de Janeiro: Objetiva, 2006.

GRADY, C. "Why some people think Shakespeare didn't write Shakespeare, explained". Vox, 2016. Disponível em: <https://www.vox.com/2016/4/22/11480192/shakepeare-400anti-stratfordian-authorship-controversy>. Acesso em: 04 de abril de 2019.

HUTCHEON, L. Uma teoria da paródia: ensinamentos das formas de arte do século XX. Trad. Teresa Louro Pérez. Lisboa: Edições 70, 1989.

Uma teoria da adaptação. 2. ed. Trad. André Cechinel. Florianópolis: Ed. da UFSC, 2013.

KEENAN, S; SHELLARD, D. "Introduction". In: Shakespeare's cultural capital: his economic impact from the Sixteenth to the Twenty-first Century. London: Palgrave Macmillan, 2016, p. 1-12.

KLENGEL, S. "From 'cultural cannibalism' to metalinguistic novel-writing". Intellectual News, v. 6, n. 1, p. 57-65, 2000.

KORKUT, N. Kinds of parody: from the Medieval to the Postmodern. 2005. $185 \mathrm{f}$. Tese (Doutorado em Ciências Sociais) - Graduate School of Social Sciences, Middle East Technical University, Ankara, 2005.

LANIER, D. Shakespeare and modern popular culture. Oxford: Oxford University Press, 2002. . "Shakespeare and cultural studies: an overview". Shakespeare, v. 2, n. 2, p. 228-

248, 2006. 


\section{$244^{\text {cineąa o \& }}$}

MASSAI, S. "Defining local Shakespeares". In: World-wide Shakespeares: local appropriations in film and performance. London: Routledge, 2005, p. 3-11.

MIGNOLO, W. Desobediência epistêmica: a opção descolonial e o significado de identidade em política. Caderno de Letras da UFF, n. 34, p. 287-324, 2008.

. The darker side of Western Modernity: global futures, decolonial options. Durham and London: Duke University Press, 2011.

MONTIRONI, M. E. "The Simpsons' Shakespeare: Hamlet today. Possible meanings and consequences of a parodic appropriation". Between, v. 2, n. 4, 2012, p. 1-20.

OLSSON, M. R. "Making sense of Shakespeare: a cultural icon for contemporary audiences". Cosmopolitan civil societies journal, v. 5, n. 3, 2013, p. 14-31.

ORKIN, M. Local Shakespeares: proximations and power. London: Routledge, 2005.

PAVIS, P. O teatro no cruzamento de culturas. Trad. Nanci Fernandes. São Paulo: Perspectiva, 2008.

RESENDE, A. da C. "Introduction: Brazilian appropriations of Shakespeare". In: Foreign accents: Brazilian reading of Shakespeare. London: Associated University Press, 2002, p. 11-41.

RINCÓN, C. "Antropofagia, reciclagem, hibridação, tradução ou: como apropriar-se da apropriação". In: ROCHA, J. C. de C.; RUFFINELLI, J. (orgs.). Antropofagia hoje?: Oswald de Andrade em cena. São Paulo: É Realizações, 2011, p. 545-560.

SANTIAGO, S. Uma literatura nos trópicos: ensaios sobre a dependência cultural. 2. ed. Rio de Janeiro: Rocco, 2000.

VERISSIMO, L. F. A décima segunda noite. Rio de Janeiro: Objetiva, 2006.

Recebido em: 27/04/2019

Aceito em: 26/05/2019

Referência eletrônica: NÓBREGA, Caio Antônio; AZERÊDO, Genilda. Devorando Shakespeare em um sonho brasileiro de uma noite de verão. Criação \& Crítica, n. 24, p., out. 2019. Disponível em: <http://revistas.usp.br/criacaoecritica>. Acesso em: dd mmm. aaaa. 